\title{
Study for an Environmental Method for Eco-materials: -Case study of Woodceramics in HRD-
}

\author{
Sakae Sunada and Toshihiro Okabe \\ POLYTECHNIC UNIVERSITY \\ 4-1-1 Hashimotodai Sagamihara Kanagawa 229-1196 Japan
}

Fax: 81-42-763-9263, e-mail: sunada@uitec.ac.jp

\begin{abstract}
Ability Development is an important national policy which is in favor of passing on skill, promoting talent, and effectively improving the environment. In this report, an enviromental material (wood ceramics) are examined as teaching materials in a based-measurment course directed by "guidance member training." The wood ceramic, which uses MDF, is a raw material from which temperature sensors will made by way of manufacturing practice. The guidance member training, in which the whole country participates, is executed with PTU. Those who participate eventually become the leaders in charge of the training. This seminar is transmitted to people of different enterprises in various places. It is important to add an environmental material to the curriculum by which we can examine the LCA.

Recently, the demand for protecting the environment has become strong. It has become necessary to control industrial waste and carbon dioxide; to use resources efficiently; and to maximized recycling. We must examine closely the material we use. Aomori Pref. is famous because of its' active agriculture and forestry industry. Its' waste from housing abolition and agriculture is a problem that has been examined, and such waste-materials can be turned into wood ceramics which are suitable for the environment. LCA is a technique of evaluating the environment and, in this thesis, the LCA of an environmental material was examined. The wood ceramics were used as an electromagnetic radiation absorbent. The LCA of the case was calculated. LCCO2 was used as an evaluation of the Global warming gas. It can contribute to the continuation of the type of society that HRD, as the national policy, approves. (Abstract, 10 point, single space, less than 200 words)
\end{abstract}

Key words: woodceramics, eco-materials, LCA, LCCO2 HRD,

\section{INTRODUCTION}

HRD is a national policy in favor of developing and promoting a person's skill. A course of training has been designed that, not only develops and promotes skill but, functions in relation to environmental policy. The wood ceramics, an enviromental material, is that which is chosen as the theme of the training. The curriculum of the "guidance member training" is introduced as a based-measurement course of training. The content of the curriculum is as follows: 1. Making of temperature sensor; 2 . Measurement of temperature characteristic; 3 . Evaluation of temperature characteristic.

The life of attending lectures consists in visiting seminars in various places; however, such a lifestyle does not entail the development or acquisition of skill. According to Arai and Shirakawa, there are three categories of skill analysis. The first is a research aiming at the personal management such as, for an example, Fujita's "Obligation analysis and personal management." The second is a research of the technique. The work decomposition of TWI serves as an example. The third is a research of the case. Arai's "Analysis of the welding skill of the coating arc" is an example of the third. However, these three are unsuitable for the analysis of the acquisition of a highly developed skill, the goal of which the HRD technique, based on the LCA evaluation, was proposed. A problematic of the the future is developing a curriculum in which LCA is added.

\section{Method}

\subsection{Target of this research}

This discourse is mainly an attempt to restructure the skill analysis technique. It is a means of handing down a highly developed skill by which an environmental material is considered. This course of training and research can influence and enpower people to such an extent that the 
environment can be turned into the type of environment in which society can continue..

\subsection{Development method to Job Ability Development of environmental material}

We paid attention, from 2002 to the sixteenth fiscal year, to the "based-measurment" curriculum of the "guidance member training" courses, specializing in areas of technology. This was "Vocational Training" provided to the public by the Job Ability Development facilities within the whole country in attempt to promote method etc. Training, of an industrial structure, was planned which corresponds to the needs in the Job Ability Development program according to the intensification of further international competition by rapid change, progress of a technological reformation, and the economic development in Asian nations etc.

The wood ceramics as an environmental material are used as a "hands-on" teaching material in the course. The development method (the goal of which, is the acquisition of new technique and skill) assumes the procedure of demonstrating the making of the teaching material.

\subsection{Aspect of three development method}

The procedure of teaching, to the making of the teaching material (i.e. the enviromental material,) is based on the next four stages

\section{First stage: Selection of development method} First of all, with respect to development method, the Job Ability Development's stance "The leader is guided" is important. It is ideal that man-to-man tutelage is the most effective form. Although this form may not be most effective with regard to spreading skill and technique with speed, this form of "guidance member training" is a model by which one leader efficiently hands down qualified skill to ten leaders or more.

\section{Second stage: Plan of curriculum}

Next, a curiculum is planned which assumes, as its' model, the "guidance member training curriculum" of both the university and the Job Ability Development programs. The content of the curriculum consists of a course number, a course name, a period, a scheduled number of days for training, a focal amount of attainment targets, a group of trainors with the specialized knowledge, content of training, the charge teachers (belonging engineering department), equipment and teaching materials, etc.

\section{Third stage: Teaching to making teaching material}

Next, relative information which supplements the content of the curriculum is arranged. This assumes the related information seat of the Job Ability Development school's "guidance member training" as a model.

The content of the seat is as follows:

Course name, level display, special area, assumption condition, acquisition element, attainment level, relating Ability Development seminar course (training course and classification number), relating ability training systems, reference books, teaching materials, and notes

\section{Fourth stage: Evaluation by LCA etc.}

It is possible to measure the influence on the environment by LCA etc. However the compilation of both "making the teaching material/enviromental material" as the curriculum based on the development method of using "guidance member training" are two main bodies that HRD evaluates.

"Course selection" and the "making of teaching material" are both of priority in the fourth stage.

\section{Result}

\subsection{Clarification of development method}

Only nine people at most from 2000 to 2004 , attended the lectures of the "based measurment" courses concerning specialized technological training in the Electronic Engineering Section. Having no people attend the training in 2004, the guidance member training ended on that fiscal year. The Job Ability Development, which assumed to be only a means of of transmitting technological training, was finished as a transitory course in addition to others.

However, junior colleges, such as Aomori Junior College, will continue practicing "guidance member training" with the aim of spreading environmental material included in its' based-measurement courses. This was the theme of graduate research from 1997 fiscal year to 2002 fiscal year. The work situation is as follows.

\subsection{Selection of method of developing the first stage}

The target, as is presented in Table 1 , is to offer the public "Vocational Training" by means of the "guidance member training" method in Job Ability Development facilities.

In the relation of the country, there exists the Polytechnic University of employment and the Ability Development Organization (ten schools); a Job Ability Development junior college (one school); Job Ability Development promotion centers (60 schools); and Job Ability Development schools for physically handicapped people nationwide (13 schools).

In relation to administrative divisions, there exists general Job Ability Development schools (207 schools); Job Ability Development schools for the physically disabled (6 schools); and Job Ability Development junior colleges ( 7 schools).

In relation to private organizations, there are Vocational Training schools (about 1600 schools); regional Vocational Training centers (82 schools); computer colleges which trains in information processing (15 schools); and Ability Development support centers (two schools), which support facilities with regard to Vocational Training.

Job Ability Development facilities of about 2000 
schools are set up in the whole country. The continuation of a type of society, based on an environmental material, will be achieved by developing the guidance member training in relation to Vocational Training in these Job Ability Development facilities.

\subsection{Plan of the second stage curriculum}

Information on the curriculum model is sent to the Ability Development research center of the Job Ability Development university school, the object of which are those who are in service training, resign training, the change of one's employment training, and graduate's training.

3.4 The third stage teaching material making 245 are registered, in the Ability Development research center, under the highly developed practice of teaching "material making".

Next, I want to arrange the LCA evaluation according to the fourth stage.

It is important, in promoting the JobAbility Development field, to calculate the amount of energy conservation (as shown in Figure-2) and to specify an economic effect as evaluated by LCA.

The use of electromagnetic shielded material for architectural purposes is possible. Moreover, the use of the fuel battery electrode etc. is examined. Each result of calculating LCA was shown in Figure-4. An economical effect of about $2,000,000,000$ yen is expected.

\section{Discassion}

\subsection{Data collection}

Wood ceramics are an old and new carbon material of which various kinds are developed. The character is conductive, sliding, heatproof, and food.

This material is used also for electromagnetic-shielding. The wood ceramics are enviromentally harmonious and will, as expected, decrease the waste problems.

However, there is little scientific data regarding the goodness wood ceramics contributes to the environment. In this thesis however, $\mathrm{LCCO} 2$ was evaluated, and an excellent result was obtained after our calculation.

Wood ceramics are produced by processing wood system wastes (e.g. abolition material, bark, old paper, and sawdust) by phenols and alcohol, with technology which completely dissolves to a general-purpose organic solvent (i.e the wood liquefaction method). The liquefied thing becomes a plastic raw material that is reborn with a new value. In this research, the reactive mechanism of each liquefied material in this method was elucidated.

Up to now, the oil system phenolic resin has been used as the stuff for wood ceramics; however, the use of the plant phenol system for liquefaction was used at this time. Thus, a new liquefaction method, into which the wood element was decomposed at a high speed and by low energy, was used in these examinations. When sulfuric acid is used as a catalyst, sulfur remains in the wood ceramics. Then, we thought that we were going to make mercury react with mercury and removed it in this case.

\subsection{Setting of each field}

The wood ceramics were manufactured using the dregs of abolition material, etc. Moreover, the ferrite was coated on account of the porous inclination. It was assumed that the absorption type electromagnetic shield material was developed as the use. LCCO2 was calculated by comparing the amounts of the crude oil consumption in manufacturing the electromagnetic shield material (wood ceramics, ferrite, and phenol resin), which used the old model electromagnetic shield material (urethane, black carbon, sheet copper, and ferrite), and the wood ceramics.

\begin{tabular}{|l|r|r|r|}
\hline & CO2/Kg & Ratio & CO2 $(\mathrm{Kg})$ \\
\hline PUR & 2.809 & $15 \%$ & 0.421 \\
\hline Polycarbonate & 3.783 & $5 \%$ & 0.189 \\
\hline Cu Sheet & 1.361 & $30 \%$ & 0.408 \\
\hline iron sintering & 0.250 & $50 \%$ & 0.125 \\
\hline \multicolumn{1}{|c|}{$\Sigma$} & & & 1.144 \\
\hline
\end{tabular}

Figure 1. Old model

\begin{tabular}{|l|r|r|r|}
\hline & $\mathrm{CO} 2 / \mathrm{Kg}$ & Ratio & $\mathrm{CO} 2(\mathrm{Kg})$ \\
\hline $\begin{array}{l}\text { Wood } \\
\text { ceramics }\end{array}$ & 0.678 & $60 \%$ & 0.407 \\
\hline iron sintering & 0.250 & $20 \%$ & 0.050 \\
\hline phenol & 0.960 & $20 \%$ & 0.192 \\
\hline \multicolumn{1}{|c|}{$\Sigma$} & & & 0.649 \\
\hline
\end{tabular}

Figure 2. New model
Old model

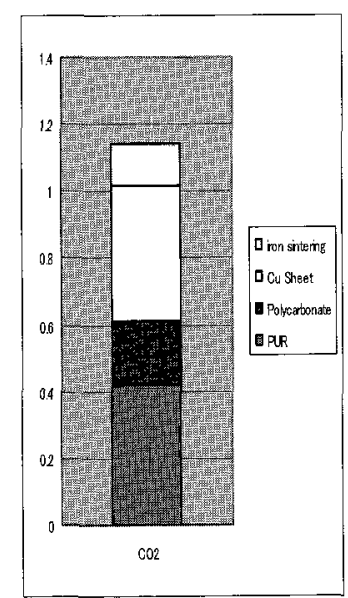

Figure 3. Results of $\mathrm{LCCO} 2$
New model

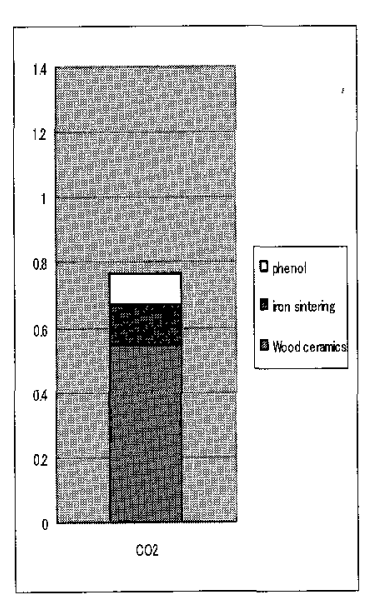




\subsection{Result of $\mathrm{LCCO} 2$}

The amount of the $\mathrm{CO} 2$ exhausted when crude oil $1 \mathrm{~L}$ was burnt was $2.84 \mathrm{~kg}$. Moreover, the amount of the crude oil reduced by replacing the wood ceramics with old goods was, from a table below, to $0.230 \mathrm{~kg}$. If the wood ceramics of $92,000 \mathrm{t}$ are used, $21,000 \mathrm{KL}$ reduction becomes possible because of the crude petroleum conversion.

\subsection{Summary of $\mathrm{LCCO} 2$}

The spread of electronic devices and the telecommunications equipment in recent years is remarkable. However, various troubles are caused by the electromagnetic radiation from such equipment. Moreover, telecommunications equipment (e.g. a portable telephone) have become personal devices, which entails a widespread concern about the influence of this equipment on the human body. This is why--and it is a well knon fact--the use of a portable telephone in the hospital is prohibited to prevent giving trouble to medical equipment.

In addition, wireless LAN will spread in the near future. Electromagnetic radiations such as ITS (highly developed road traffic system) and ETS (automatic expressway account system) will be highly used in this infrastructure. Moreover, the frequency area is extending from the semi-millimeterwave belt to the millimeterwave belt. Thus, the electromagnetic radiation trouble shows the tendency to increase more and more. As a means of problem solving, it is urgent to develop a new material, insofar as electromagnetic radiations will the flood the age to come.

We should defend each home and the transportation network, etc. from possible malfunctions due to influence of electromagnetic radiation. It is necessary to consider the measures and futher the development of electromagnetic radiation shield material. This research, in its present stage, and when compared with the old model, has a merit of cheapness, and lightness, and conservative with respect to energy.

\section{Conclusion}

A curriculum which uses, as its' tecahing content, environmental material has been examined under the Job Ability Development system of the "guidance member training." We reported that the wood ceramics would be made a teaching material so that an environmental material might be applied under this research thesis.

It seems that an economical effect is looked by the LCA evaluation, we does not come, and the spreading technique gives us one suggestion. And, this research is profitable for the continuity of society.

Referebces

[1] Itsubo, N.and Inaba A.,Life cycle impact assessment method, Japan Environmental Management Association for Industry
(JEMAI)(2005),(In Japanese)

[2] METI,Green Servicizing, Ministry of Environment, Trade and Industry of Japan, online accessed at http://www.meti.go.jp/policy/eco business/servic izing/[March 19,2006],(In Japanes).

[3] Goro ARAI \& Kotaro SIRAKAWA.,The Study on Objectivity of the SKILL-The point of view from the systematized technique of the digitization affair of the skilled skill-,(JSSVTE)(2005), (In Japanese)

[4] Kohei MORIMOTO,Hong X,NGUYEN,Miki CHIHRA, Tomonori HONDA and Ryoich YAMAMOTO,Proposals for Classification and an Environmental Impact Evaluation Method for Eco-Services:Case study of Municipal Waste Treatment in Cement Production,Journal of Life Cycle Assessment,Japan,Vol.2 No.4 [October,2006]

(Recieved June 6, 2008 ; Accepted September 5, 2008) 